\title{
Bacteriophage Typing of Shigella sonnei
}

\author{
RUDY C. PRUNEDA AND J. J. FARMER III* \\ Department of Parasitology and Laboratory Practice School of Public Health University of North Carolina \\ Chapel Hill, North Carolina 27514, and Bacteriophage-Bacteriocin Laboratory, Center for Disease Control, \\ Atlanta, Georgia 30333*
}

Received for publication 22 September 1976

\begin{abstract}
A bacteriophage-typing schema was developed for differentiating strains of Shigella sonnei. Sixty-seven bacteriophages were obtained from other collections, and 36 bacteriophages were isolated from sewage. From these 103 bacteriophages, a provisional set of 12 was chosen by computer analysis as being the most sensitive in differentiating strains of $S$. sonnei isolated in the United States. The provisional schema was used to type 265 strains from different geographical areas. It divided them into 87 different lysis patterns, and all 265 strains were typable. Smooth and rough colonial variants of the same strain had different lysis patterns, so the technique was standardized to type rough colonies only. Reproducibility was difficult to obtain until all conditions were carefully standardized. Changes in results were noted even on different lot numbers of Trypticase soy agar, which was defined as the standard medium. So that the medium would not be a variable, 100 pounds (ca. $453.5 \mathrm{~kg}$ ) of the same lot number was purchased. Bacteriophage typing was very useful in differentiating strains, and work should continue on establishing a standardized schema.
\end{abstract}

In many parts of the world, Shigella sonnei has become the predominant species of Shigella. In the United States, $S$. sonnei accounts for about $85 \%$ of all Shigella isolates, $S$. flexneri accounts for about $14 \%$, and $S$. dysenteriae and $S$. boydii account for only about $0.5 \%$ each (7). S. sonnei is found in all regions of the United States and is often endemic in institutions for the mentally ill, on Indian reservations, and in day-care centers and communities of lower socioeconomic status (10).

Each species of Shigella except $S$. sonnei can be divided into serotypes (9), and serological subdivision is usually sufficient for tracing the epidemiology of $S$. dysenteriae, S. Flexneri, and $S$. boydii (7). However, other methods must be used for the epidemiological fingerprinting of S. sonnei. Szturm-Rubinstein (29) used beta-galactosidase, xylose, and rhamnose as markers in biotyping. Abbott and Shannon (1) developed a method based on colicin production (colicins are antibiotic substances produced by strains of Escherichia coli, Shigella, and related species that kill other strains of these same species), and this typing method has often been used as an epidemiological marker $(16,26)$. Resisto-typing (growth inhibition by organic and inorganic chemicals) has been used by Elek et al. $(11,23)$. Antibiograms $(4,8)$ and phage typing $(19,22,28)$ have also been used to differentiate strains of $S$. sonnei, and combinations of several typing methods have also been used $(4,14,20)$.

In the United States, colicin production (16) has been the most common method for typing S. sonnei. Unfortunately, in recent years, $40 \%$ of the $S$. sonnei isolates from outbreaks have not produced colicins that kill any of the colicin indicator strains and thus have been "untypable" (23). A similar problem exists in England; Gillies (17) found that $79.5 \%$ of the $S$. sonnei cultures were untypable in 1963 and $92.3 \%$ were untypable in 1964.

Of all the typing methods, bacteriophage typing appears to be the most sensitive; therefore, the purpose of this study was to evaluate phage-typing schemas that others have used and to select the most useful phages for a provisional schema. A future article compares bacteriophage typing, colicin typing, and antibiograms as epidemiological markers in the surveillance of outbreaks due to $S$. sonnei.

\section{MATERIALS AND METHODS}

Media. Trypticase soy agar (TSA), Trypticase soy broth (TSB), and Mueller-Hinton agar were obtained from Bioquest (Div. of Becton, Dickinson \& Co., Cockeysville, Md.) and were prepared according to the manufacturer's instructions. Soft agar for overlays contained $0.4 \%$ (wt/vol) Oxoid Ionagar no. 2 (Colab Laboratories, Inc., Chicago, Ill.). Phage agar contained nutrient broth (Difco Laboratories, Detroit, Mich.), $20 \mathrm{~g}$; $\mathrm{NaCl}, 7.5 \mathrm{~g}$; agar-agar, $20 \mathrm{~g}$; 
and distilled water, $1,000 \mathrm{ml}$. All other media were from commercial sources and were prepared by the Media Unit at the Center for Disease Control (CDC). All dilutions of bacteriophages in host strains were in either phage broth or TSB. All incubations were at $36 \pm 1^{\circ} \mathrm{C}$, and all phages were stored at $4^{\circ} \mathrm{C}$.

Bacterial strains. Three hundred isolates of $S$. sonnei, 15 isolates of $S$. boydii, 15 isolates of $S$. flexneri, and 5 isolates of $S$. dysenteriae were obtained from the Enteric Section, CDC; these samples had been sent to CDC from throughout the United States. Species and serotypes for all cultures had been identified by the WHO Collaborating Centre for Shigella. Additional cultures were obtained from the Enteric Section, CDC; $S$. sonnei strains were from the Medical Bacteriology Unit, Texas Health Resources, Austin, Tex., and a number of Enterobacteriaceae came from the stock culture collection of the Parasitology and Laboratory Practice Department, School of Public Health, University of North Carolina, Chapel Hill. All cultures were stored in sealed test tubes at room temperature in the dark.

Bacteriophages. Sixty-seven bacteriophages were obtained from the following collections: 13 phages used in typing Escherichia coli (25) from J. T. Parisi, Department of Microbiology, University of Missouri, Columbia, Mo.; 12 phages used in typing $S$. flexneri from C. Ciufecu, Bucharest, Romania; 10 phages used in a provisional typing schema for $S$. sonnei (28) from S. Slopek, Polish Academy of Sciences, Wroclaw, Poland; and 32 phages from the Bacteriophage-Bacteriocin Laboratory, CDC.

Isolation of bacteriophages from sewage. Samples of raw sewage were collected from the sewage treatment plant, Chapel Hill, N.C., and pooled. Bacteriophages in the sewage were isolated by the enrichment method of Adams (2), modified as follows. (i) Each host strain was inoculated into TSB and grown (overnight) to the stationary phase. Then $0.1 \mathrm{ml}$ of the culture and 2 to $4 \mathrm{ml}$ of the raw sewage were added to $9 \mathrm{ml}$ of TSB in an 18- by $15-\mathrm{mm}$ tube and incubated for 6 to $7 \mathrm{~h}$ at $35^{\circ} \mathrm{C}$. (ii) A $0.3-\mathrm{ml}$ amount of chloroform was added to $3 \mathrm{ml}$ of the host-sewage mixture; the tube was vigorously shaken with a Vortex mixer, and the chloroform was allowed to settle for about $1 \mathrm{~h}$ at $4^{\circ} \mathrm{C}$. (iii) A $0.3-\mathrm{ml}$ portion of the top layer was removed into a petri dish, which was placed in a hood with laminar air flow to remove the residual chloroform. (iv) Serial 100 -fold dilutions were made of the enrichment and dropped onto a lawn of the host on TSA. After the drops had dried, the plates were incubated overnight and observed for bacteriophage plaques. (v) Single isolated plaques were picked and added to $10^{6}$ cells of the host strain in TSB. This was necessary to obtain a stock with a titer of more than $10^{8}$ plaque-forming units (PFU)/ml. (vi) This mixture was then treated with chloroform, as in step iii, and stored.

Thirty-six bacteriophages were isolated from sewage: 8 on $S$. sonnei; 9 on S. flexneri; 3 on S. dysenteriae; and 16 on E. coli. Each of the 36 host strains was from a different source; thus, diversity of the phages was insured.

RTD. Serial 10-fold dilutions were made of each of the final phage preparations, and each dilution was tested against the host strain on TSA. Based on this titration, a tube of phage that contained $10^{6} \mathrm{PFU} / \mathrm{ml}$ was made, and this was called the routine test dilution (RTD) tube. Our standard syringes were filled from the RTD tubes. Since each syringe delivers drops of $0.01 \mathrm{ml}$, each drop contains $10^{4} \mathrm{PFU}$ of phage. We define our RTD to be $10^{4}$ PFU of phage $\left(10^{6} \mathrm{PFU} / \mathrm{ml} \times 0.01 \mathrm{ml}=10^{4} \mathrm{PFU} /\right.$ test $)$, thus abandoning less precise definitions previously used for RTD such as "that producing confluent or semiconfluent lysis" (3). Two titrations are shown in Fig. 1.

Bacteriophage typing. Initially, whole cultures were used for the phage-typing procedure; however, we soon learned that the lysis patterns were dependent on the ratio of smooth to rough colonies present in the culture.

Lawns for phage typing were prepared as "flood
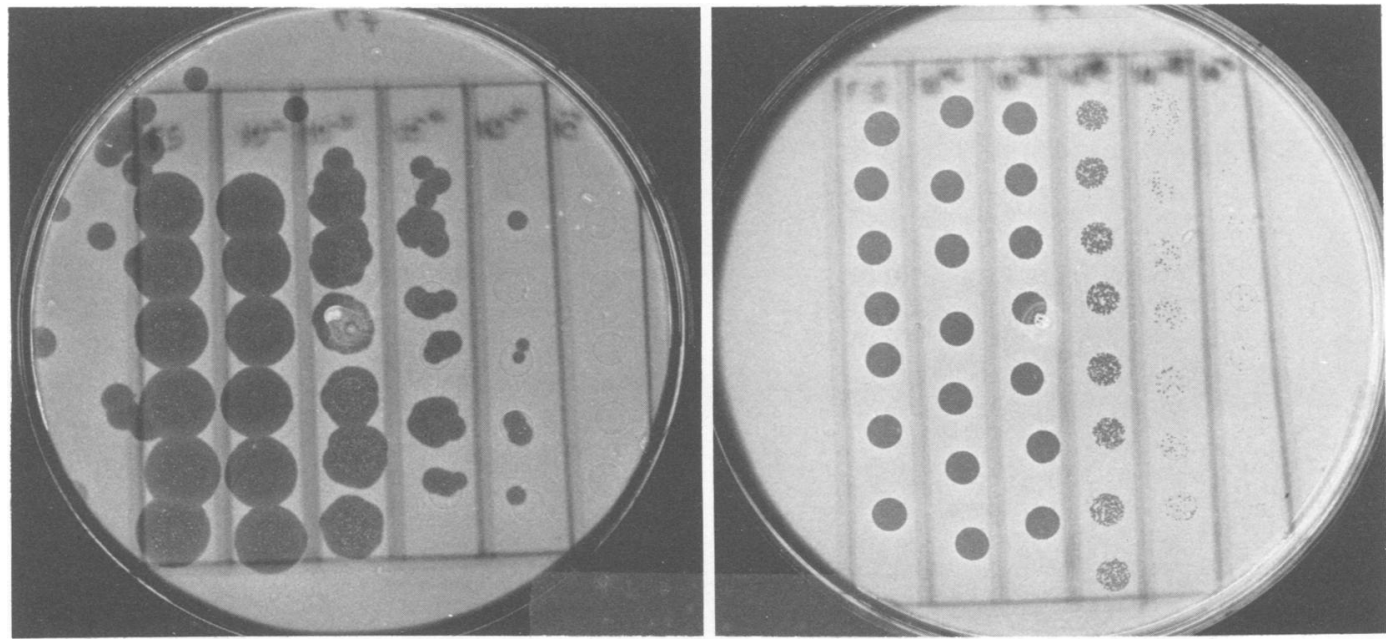

Fig. 1. Tenfold dilutions of phage F7 (left) and F9 (right) on their host strains. 
plates" from rough colonies. TSA plates were dried either for 30 min under laminar air flow or with the tops on in room air for $72 \mathrm{~h}$. The dry plates were flooded with a broth culture that had been adjusted to the standard turbidity (optical density at $650 \mathrm{~nm}$ $=0.10$, with a light path of $1.3 \mathrm{~cm}$ ). This turbidity is almost identical to a 0.5 MacFarland standard used in antimicrobial sensitivity testing. The excess fluid was removed with a safety pipette and discarded into $0.5 \%$ (wt/vol) Amphyl (National Laboratories, Toledo, Ohio). The plates were dried with the tops off for $10 \mathrm{~min}$; the phages (at RTD) were then applied simultaneously with the applicator shown in Fig. 2 (Johnny Brown Machine Shop, Tuscaloosa, Ala.). This applicator delivers 61 uniform drops in a single operation. After the drops had dried, the plates were incubated overnight and observed by indirect lighting with a model $\mathrm{C} 100$ electronic colony counter (New Brunswick Scientific, New Brunswick Co., N.J.) for lysis. An area of lysis with 20 or more plaques was defined as positive; however, all results were recorded as confluent lysis or semiconfluent lysis and as to size and number of plaques seen per drop. The nomenclature was that of Anderson and Williams (3). The lysis patterns were converted to numbers by using the simplified notation described by Farmer (12) (Table 1). Thus, the phage type in our provisional schema consisted of a four-digit number and represented its reaction against our best 12 bacteriophages.

Selection of standard set of bacteriophages. The best bacteriophages were selected on the basis of a computer analysis as described by Farmer (13) and developed by Milton Hutson and John Zakanycz, Computer Honors Program, University of Alabama, Tuscaloosa, Ala. Computer analysis from 340 isolates of $S$. sonnei indicated that the best set for routine typing consisted of 12 phages; this set was defined as the provisional set in the typing procedure.

Smooth and rough colony types. Cultures of $S$. sonnei were streaked on TSA or Tergitol-7 (Difco) agar plates and incubated overnight; isolated colonies were observed under a dissecting microscope with oblique lighting. The smooth and rough colonies observed were similar to those described by Baker et al. (5) (see Fig. 3). The lysis patterns of the smooth and rough colonies were compared as described previously (12). Serological typing was done with $S$. sonnei antisera (Bioquest, Cockeysville, Md.) from growth taken from TSA plates. Acriflavine was also used to detect roughness (6). Smooth colonies were streaked on TSA plates, incubated overnight, and observed for both rough and smooth colonies. Both colony types were then phage typed.

Comparison of the Slopek phage set and new set. Two hundred and sixty-five isolates of $S$. sonnei

TABLE 1. Simplified notation for reporting bacteriophage types ${ }^{a}$

\begin{tabular}{cc}
\hline Results of three tests & Representation \\
\hline+++ & 1 \\
++- & 2 \\
+-+ & 3 \\
-++ & 4 \\
+-- & 5 \\
-+- & 6 \\
--+ & 7 \\
--- & 8 \\
\hline
\end{tabular}

a If the number of tests is not evenly divisible by 3 , a second $(++=\mathrm{A},+-=\mathrm{B},-+=\mathrm{C},--=\mathrm{D})$ and third $(+=E,-=F)$ code can be used to represent those results remaining after division by 3.

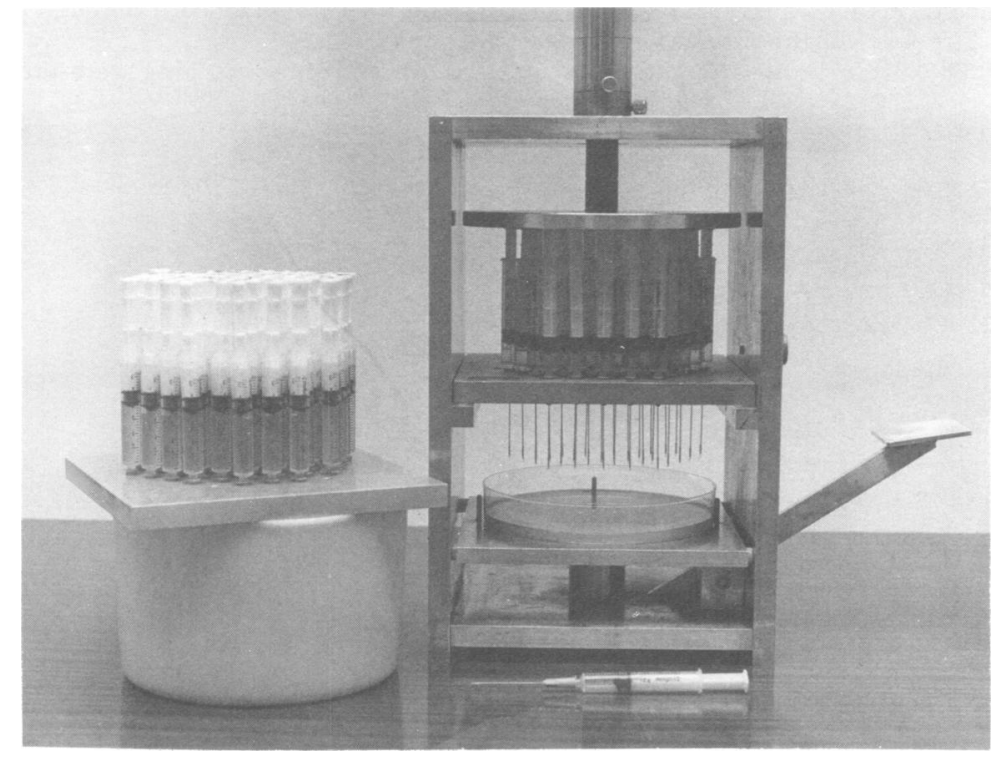

Fig. 2. Bacteriophage applicator with syringes containing the bacteriophages at RTD. 
were obtained from the CDC collection. These cultures were from throughout the United States and were submitted over a period of 20 years. The strains were then typed with our provisional set of 12 phages and the Slopek set of 10 phages (28).

\section{RESULTS}

Effect of colonial variation on typing results. Figure 3 shows the two types of colonies (defined to be rough [r] or smooth [s]) usually seen in plates streaked for isolation. The smooth colonies were round and moist; the rough colonies were dry, granular, and flat and had irregular borders. Both of these colony types had characteristic agglutination reactions (Fig. 3) in commercial S. sonnei antisera.
This type of agglutination was not observed in acriflavine or in antisera to $S$. sonnei (phage I or II) prepared at CDC.

Figure 4 shows the lysis patterns of rough and smooth colony types derived from the same strain $(\mathrm{m} 7480)$. The first 12 phages are the provisional set described in this paper. The rough colony type is lysed by 18 phages, but the smooth colony type is lysed by only 6 . Thus, the lysis patterns of smooth and rough colonies were different even though they were derived from the same strain. This is why the technique was standardized for typing only the rough colonies. When the whole culture (no selection for rough or smooth) of $S$. sonnei 7748 was phage typed, it had a lysis pattern intermediate be-
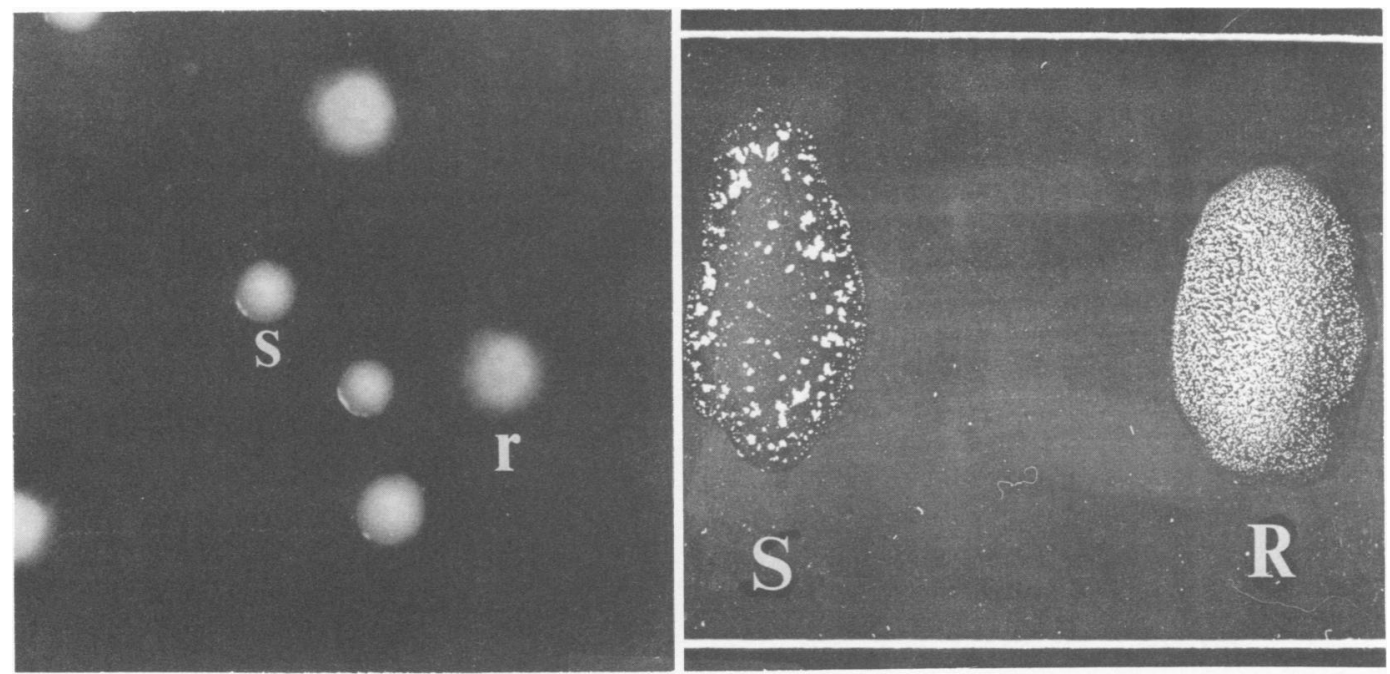

FIG. 3. Smooth (s) and rough ( $r$ ) colonies of $S$. sonnei (left) and agglutination of smooth $(S)$ and rough $(R)$ colonies with antisera for $\mathrm{S}$. sonnei (right).
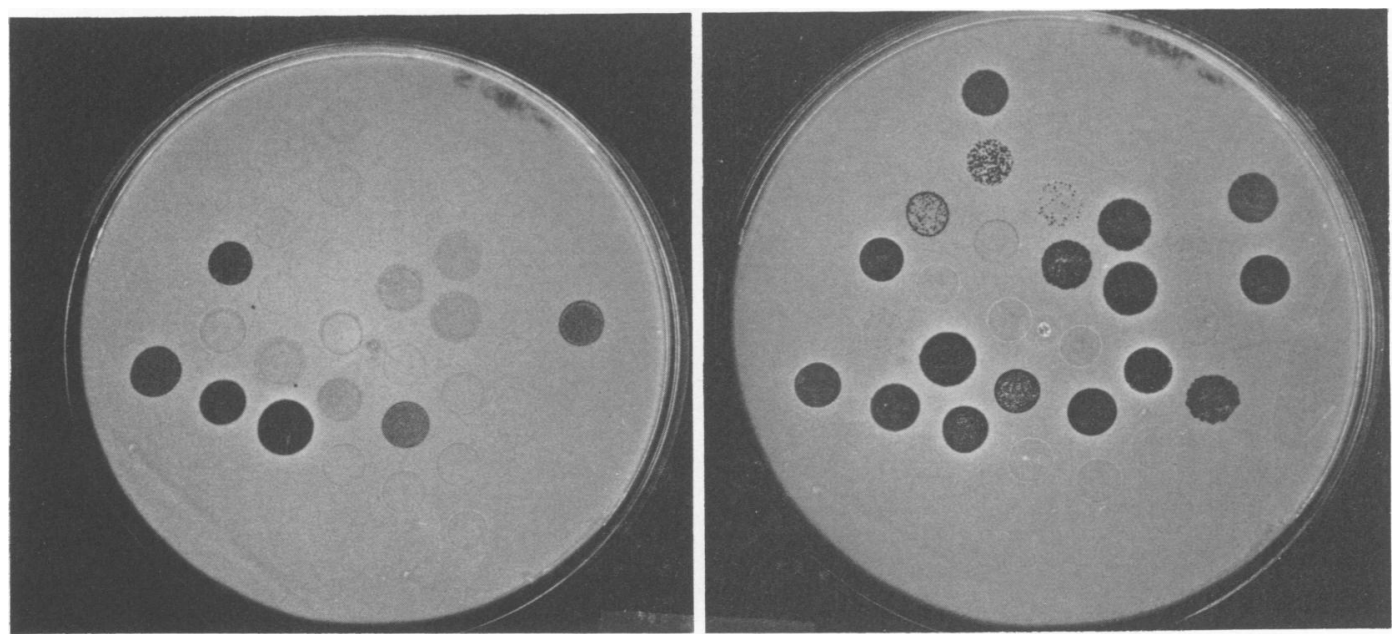

FIG. 4. Lysis patterns of a smooth colony (left) and a rough colony of the same strain (right). 
tween rough and smooth, which probably reflected the proportions of rough and smooth colonies in the culture.

Effect of media on typing results. Figure 5 shows different lysis patterns of Slopek's strain 1393 of $S$. sonnei on phage agar and TSA. Six phage reactions were media dependent. After trying both media, we decided to use TSA in standardizing the provisional typing schema, for the following reasons: (i) TSA was available commercially, but phage agar was not; (ii) TSA was easier to prepare and pour; and (iii) drops of phage did not spread or run together on TSA, as they often did on phage agar.

Selection of the best 12 bacteriophages. One hundred and three bacteriophages were evaluated. Many of these were eliminated for one or more of the following reasons: (i) they lysed only a small percentage of the $S$. sonnei strains; (ii) they gave reactions that were difficult to read and reproduce; or (iii) they gave lysis patterns too similar to those of other, more useful phages. Many of the phages were eliminated by impartial computer analysis. An example of how the computer program works is shown in Fig. 6. Here, 145 isolates had been tested against 72 phages which yielded over 10,000 reactions. The first step in the program is to choose the phage that best divides the 145 isolates into two groups, with half being lysed and half not being lysed. None of the phages made this division exactly, but phage P1 came the closest $(75+, 70-)$; thus, it was chosen first. The program then chose the phage that best divided the two groups formed by the first phage. In this case, P2 was chosen because it divided the two groups with the most equal subdivisions. With $\mathrm{P} 1$ and $\mathrm{P} 2$, the 145 strains would now be divided into four groups $(++, 40$ strains; +-, 35 strains,,-+ 36 strains; - - 34 strains). The program then continues to select phages that best subdivide the groups formed by the previous selections. Figure 6 shows the actual analysis for the first three phages chosen and how they divided the 145 strains into eight different "plus-minus" patterns. The program continues to choose the best phages until a level (set by user) of sensitivity (or number of phages) is reached. Table 2 shows the 12 phages chosen by computer analysis as being the most sensitive. Of these 12 phages, four had been used in Slopek's typing schema for S. sonnei, two came from a typing set for $S$. flexneri, three came from the CDC collection, and three had been isolated from sewage.

Table 3 shows that the phages divided 265 isolates of $S$. sonnei into 88 different lysis patterns. In this table, the phage type consists of a four-digit number that represents the 12 phage reactions. Type 1111 was the most common and comprised $20 \%$ of all isolates. Types 2111,2211 ,

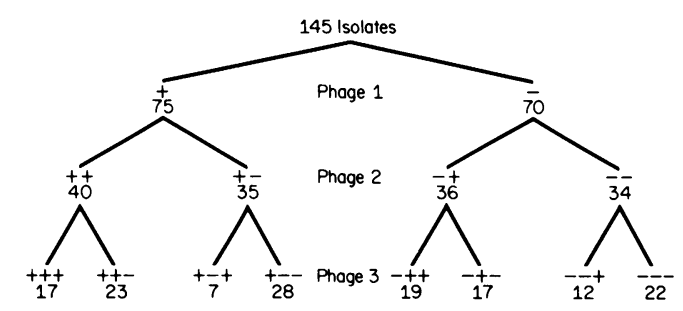

Fig. 6. Example of how the computer program chose the first three phages and divided the 145 strains into different patterns.
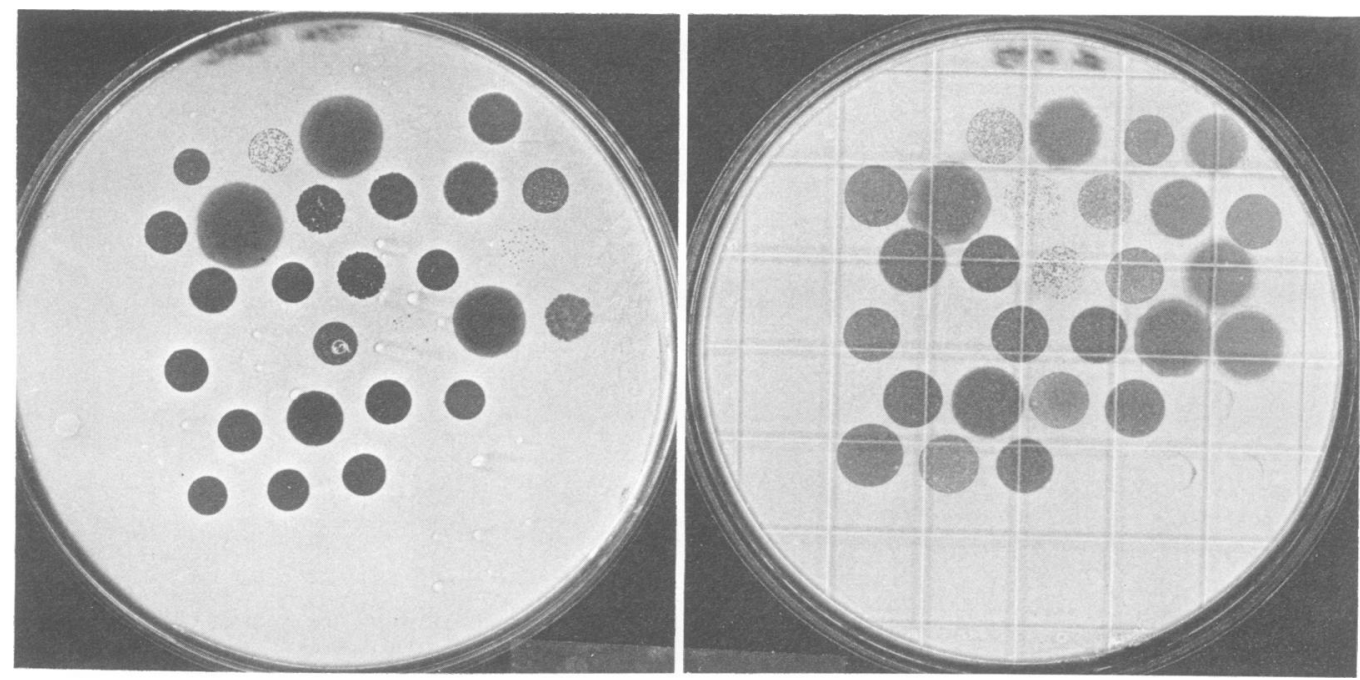

FIG. 5. Lysis pattern of S. sonnei Slopek 1393 on TSA (left) and phage agar (right). 
TABLE 2. Bacteriophages selected for final typing system

\begin{tabular}{cclc}
\hline $\begin{array}{c}\text { New } \\
\text { phage } \\
\text { designa- } \\
\text { tion }\end{array}$ & $\begin{array}{c}\text { Old } \\
\text { phage } \\
\text { designa- } \\
\text { tion }\end{array}$ & \multicolumn{1}{c}{ Source } & $\begin{array}{c}\text { Lysis of } \\
\text { strains } \\
\text { lysed (\%) }\end{array}$ \\
\hline P1 & SS4a & Sewage & 52 \\
P2 & 18 i & Enteric collection & 53 \\
P3 & F7 & Slopek & 35 \\
P4 & 34b & Enteric collection & 57 \\
P5 & EC5 & Sewage & 63 \\
P6 & 19c & Enteric collection & 45 \\
P7 & F4 & Slopek & 69 \\
P8 & R9 & Ciufecu & 84 \\
P9 & F3 & Slopek & 80 \\
P10 & SD2 & Sewage & 90 \\
P11 & F1 & Slopek & 89 \\
P12 & R7 & Ciufecu & 77 \\
\hline
\end{tabular}

4111 , and 4511 were also common, but the remaining types were rare. All 265 strains were lysed by at least one phage, so all were typable.

Slopek's phage set (28) was also used to type these same 265 isolates (Table 4). Both sets typed all of the isolates; however, our provisional phage set was more sensitive. It divided the isolates into 88 types, as compared to 34 for Slopek's set, and also considerably reduced the size of the most common types (Table 4).

Colicin typing of the 265 isolates. The 265 isolates that were phage typed were also colicin typed by CDC's Epidemiologic Investigation Laboratory Branch. Colicin typing showed that $35.7 \%$ were untypable. The next largest groups were types 7 and 9 , with 12.7 and $12.3 \%$, respectively. These were followed by colicin types 2 (11.5\%), $12(9.12 \%)$, and $6(7.9 \%)$. Twelve groups were differentiated by this method.

\section{DISCUSSION}

Shigellosis due to $S$. sonnei is a problem in the United States. People on Indian reservations and in mental institutions and those in low-income areas are most susceptible, because they are often undernourished, lack proper sanitary facilities, and generally practice poor hygiene (15). To better understand the epidemiology of these infections, a sensitive typing system is needed. This could help pinpoint the sources of infection and reduce the likelihood of further spread. Such a system would give the epidemiologists reliable, sensitive, and fast results, especially when an outbreak is in progress.

Recent work by Slopek et al. (28) has indicated that bacteriophage typing could become the method of choice for studying outbreaks from $S$. sonnei. They selected their 10 phages from those that had been previously used for
TABLE 3. Distribution of 265 isolates of $S$. sonnei into phage types

\begin{tabular}{|c|c|c|c|}
\hline Phage type & $\begin{array}{l}\text { No. of iso- } \\
\text { lates }\end{array}$ & Phage type & $\begin{array}{l}\text { No. of iso- } \\
\text { lates }\end{array}$ \\
\hline 1111 & 54 & 3111 & 8 \\
\hline 1113 & 1 & 3123 & 1 \\
\hline 1123 & 1 & 4111 & 12 \\
\hline 1141 & 5 & 4211 & 1 \\
\hline 1311 & 2 & 4311 & 2 \\
\hline 1321 & 1 & 4312 & 1 \\
\hline 1352 & 1 & 4321 & 4 \\
\hline 1411 & 1 & 4323 & 1 \\
\hline 1632 & 1 & 4324 & 1 \\
\hline 2111 & 12 & 4332 & 2 \\
\hline 2132 & 1 & 4433 & 1 \\
\hline 2211 & 14 & 4613 & 1 \\
\hline 2141 & 2 & 4811 & 1 \\
\hline 2232 & 1 & 4841 & 1 \\
\hline 2241 & 4 & 5111 & 8 \\
\hline 2321 & 1 & 5132 & 1 \\
\hline 2432 & 3 & 5141 & 1 \\
\hline 2611 & 3 & 5211 & 15 \\
\hline 2613 & 2 & 5214 & 3 \\
\hline 2643 & 1 & 5216 & 1 \\
\hline 2661 & 1 & 5244 & 1 \\
\hline 2811 & 3 & 5311 & 1 \\
\hline 2821 & 1 & 5611 & 5 \\
\hline 2852 & 2 & 5613 & 1 \\
\hline 5613 & 1 & 8211 & 1 \\
\hline 5614 & 3 & 8612 & 1 \\
\hline 5632 & 1 & 8822 & 2 \\
\hline 5811 & 1 & 8841 & 1 \\
\hline 5832 & 1 & 8842 & 1 \\
\hline 5862 & 1 & 8844 & 1 \\
\hline 6111 & 13 & 8845 & 1 \\
\hline 6141 & 3 & 8846 & 1 \\
\hline 6211 & 3 & 8861 & 2 \\
\hline 6161 & 1 & 8862 & 5 \\
\hline 6314 & 1 & 8864 & 1 \\
\hline 6341 & 2 & 8866 & 1 \\
\hline 6541 & 1 & 8872 & 5 \\
\hline 6561 & 1 & 8875 & 4 \\
\hline 7611 & 1 & 8876 & 2 \\
\hline 7613 & 1 & 8882 & 1 \\
\hline 7711 & 1 & & \\
\hline 7786 & 1 & & \\
\hline 7811 & 1 & & \\
\hline 7862 & 1 & & \\
\hline 7821 & 1 & & \\
\hline 7853 & 1 & & \\
\hline 7861 & 1 & & \\
\hline
\end{tabular}

typing $S$. sonnei $(18,19,27)$. Thus, in establishing their system, they used the best phages from these previous typing streams. All of the $S$. sonnei strains that they tested were typable, and the phage set divided the 2,064 isolates tested into 100 types with their provisional phage set one and into 85 types with provisional set two. Because of Slopek's excellent studies, we decided to evaluate this typing set with 265 isolates of $S$. sonnei from the United States. 
TABLE 4. Sensitivity of two typing schemas in differentiating 265 isolates of S. sonnei

\begin{tabular}{|c|c|c|c|c|c|c|c|c|}
\hline \multirow[b]{2}{*}{ Phage set } & \multirow{2}{*}{$\begin{array}{l}\text { No. of un- } \\
\text { typable }\end{array}$} & \multirow{2}{*}{$\begin{array}{l}\text { No. of dif- } \\
\text { ferent } \\
\text { phage types }\end{array}$} & \multicolumn{6}{|c|}{$\%$ of isolates in common phage types: } \\
\hline & & & $\begin{array}{l}\text { 1st most } \\
\text { common }\end{array}$ & $\begin{array}{l}\text { 2nd most } \\
\text { common }\end{array}$ & $\begin{array}{l}\text { 3rd most } \\
\text { common }\end{array}$ & $\begin{array}{l}\text { 4th most } \\
\text { common }\end{array}$ & $\begin{array}{l}\text { 5th most } \\
\text { common }\end{array}$ & $\begin{array}{l}\text { 6th most } \\
\text { common }\end{array}$ \\
\hline Slopek & 0 & 34 & 34 & 26 & 6 & 4 & 3 & 3 \\
\hline This study & 0 & 88 & 20 & 5 & 5 & 4 & 4 & 3 \\
\hline
\end{tabular}

One criterion for a good typing system is that the phages should divide the isolates into a sufficient number of phage types (3). Our $265 \mathrm{~S}$. sonnei isolates were divided into 88 phages types. In comparison, Slopek's phage set divided these same isolates into only 34 phage types. In addition, the percentage of the isolates in the most common phage types were much smaller with our typing system than with Slopek's. With our new phage set, the largest phage type comprised $20 \%$, which is the most sensitive reported to date $(2,18,21,22)$.

The second criterion is that the technique should be simple and give clear-cut results. The procedure for making lawns and the automated application of bacteriophages have eliminated the cumbersome process of applying individual phages (3). Clear-cut areas of lysis were usually obtained with the new phage set, especially when rough colonies were used. Another factor that influenced the readings was the end point used for designating a reaction as positive. For the new typing set, an RTD of $10,000 \mathrm{PFU} /$ test was used, and a positive reaction was defined to be the presence of 20 or more bacteriophage plaques. These two criteria may be modified in the future if reproducibility proves to be better with a different end point or RTD. This point should be investigated further before a standardized method is proposed. The criterion chosen for defining a phage type was broad compared with that selected by Slopek et al. (28). In the Slopek system, the difference between some phage types was based on very small variations in lysis between the reactions of the same phage. For this reason, it was difficult to compare the phage types seen in the United States with those seen in Poland. Several modificatons could be tried to improve the test results. One modification would be to use a media such as Tergitol agar to convert all smooth strains into rough strains, thus insuring uniformity of colony types used for typing. This, along with changes in the RTD and end point, could improve the results.

The third criterion is that the typing reagents should be stable. There was very little drop in titer of any of the typing phages, even though some had been stored at $4^{\circ} \mathrm{C}$ for as long as 6 months.

The fourth criterion is that the results should be available quickly. The method of making lawns and applying phages with an applicator has eliminated many of the time-consuming procedures used previously. Phage typing is much quicker than colicin typing for these reasons. Colicin typing is best suited for typing a large group of cultures together, because of the methodology and quality control required. In contrast, phage typing is equally suited for typing 1 or 100 strains in one run, since only one or two control strains are needed to indicate whether the phages are at the proper RTD. Our results were often available within $8 \mathrm{~h}$ of receipt of the culture.

The fifth criterion is the most important; it is that typing results should agree with epidemiological findings. In the past, this important criterion has not been satisfied with many typing systems. Abbott and Shannon (1) described typing by colicin sensitivity along with typing by colicin production; however, they rejected colicin sensitivity as a typing tool because of its poor agreement with epidemiological findings. Any new typing method should be compared with other systems to verify its accuracy and reliability. For this reason, phage typing was compared with colicin typing and antibiograms. These data appear in a companion paper (in preparation), but it can be said that there was usually excellent agreement between phage-typing results and epidemiological data.

Rough and smooth forms of the same culture greatly influenced the typing results. This has often been a problem in phage typing (3). "Vipositive" and "Vi-negative" cultures of Salmonella typhi react differently to typing phages (3), as do different colony types of Pseudomonas aeruginosa (30). When the first $S$. sonnei isolates were phage typed, whole cultures were used without regard to possible colony type variation; however, it became apparent that this would not work. Rough colony types produced the best lysis; other investigators typing $S$. sonnei $(18,19)$ and still others doing colicin typing (29) have noticed this. The degree of lysis by 
whole cultures depended on the proportion of rough or smooth colonies found. Thus, the culture must be streaked and rough colonies must be picked for typing. Most cultures, however, have reverted to the rough form by the time they reach us, so whole cultures can be used if speed is essential to an epidemiological investigation. However, these results should be confirmed with rough colonies.

Medium was also an important variable, since quite different results were obtained with TSA and phage agar. A final decision to use TSA was based on a number of practical considerations. A single lot number of this medium is now used in all phage typing at the National Center for Enteric Phage Typing at CDC. This is because quite different results were obtained with batches of TSA made from agar-agar with different lot numbers. For these reasons, we recommend that others buy many bottles of the same lot number and do all typing on this standardized medium. This would eliminate media as a variable. When the variables of colony types and media were eliminated, the typing results became reproducible.

Like Slopek (28), we selected our provisional set of phages from a large number that were evaluated. By comparing the Slopek set with our new set, we showed that the latter is more sensitive; it was capable of dividing the large groups formed with the Slopek set into smaller groups, thus revealing its greater sensitivity.

Another factor that could limit the epidemiological usefulness of phage typing is that $20 \%$ of the 265 isolates were of one bacteriophage type (Table 3). Laszlo and Kerekes (20) recommended that such groups be divided by colicin typing, Rishe (27) suggested that adding temperate phages to the phage set might break up these large groups. Antibiograms may also by useful in subdividing these groups; however, $\mathbf{R}$ factor acquistion by an isolate can easily change the resistance pattern. Therefore, isolates with different antibiograms are not necessarily different strains.

The new phage-typing system may prove useful for typing other members of the genera Shigella and Escherichia. With the addition of other bacteriophages from collections or sewage, strains of certain serotypes that predominate in certain areas of the country can perhaps be differentiated. Possibly, phages could be selected that are specific for that particular genus or species. For this reason, a reevaluation could show phages that might be used in the prophylactic treatment of shigellosis, such as those Mulezyk and Slopek (24) used in Poland. These workers have used phages that lyse most of the
$S$. sonnei strains in their country. With the aid of sodium bicarbonate to neutralize stomach acidity, a phage solution has been given orally with good success. This approach is theoretically possible in any country.

Our results suggest that a standardized phage typing system for $S$. sonnei can be established in the United States. Since this phage set is composed of the best phages from other colections, a typing set with worldwide coverage can also be established. Typing results of strains throughout the country indicate that regional centers could do surveillance. Such a system has been established at designated state laboratories and at CDC for S. typhi. We hope that a similar system for $S$. sonnei can be implemented.

\section{ACKNOWLEDGMENTS}

This research was performed as a part of the Laboratory Practice Training Program, School of Public Health, University of North Carolina, in cooperation with the Bureau of Laboratories, Center for Disease Control, Atlanta, Ga., and was supported by research grant $\mathrm{CC} 00606$ from the Center for Disease Control.

We thank S. Slopek, J. T. Parisi, and C. Ciufecu for their bacteriophage sets, J. P. Zakanycz for his computer analysis, and Joy Wells and Lynn Matsen for colicin typing.

\section{LITERATURE CITED}

1. Abbott, J. D., and R. Shannon. 1958. A method of typing Shigella sonnei using colicine production as a marker. J. Clin. Pathol. 11:71-77.

2. Adams, M. H. 1959. Bacteriophages. John Wiley and Sons, Inc., New York.

3. Anderson, E. S., and R. E. O. Williams. 1956. Bacteriophage typing of enteric pathogens and staphlococci and its use in epidemiology. J. Clin. Pathol. 9:94-127.

4. Aoki, Y. 1868. Colicin type, biochemical type, and drugresistance patterns of Shigella sonnei isolated in Japan and its neighboring countries. Arch. Immunol. Ther. Exp. 16:303-313.

5. Baker, E. E., W. E. Goebel, and E. Periman. 1948. The specific antigens of variants of Shigella sonnei. J. Exp. Med. 89:325-338.

6. Braun, W., and A. E. Bonestell. 1947. Independent variation of characteristics in Burcella abortus variants and their detection. Am. J. Vet. Res. 8:386-390.

7. Center for Disease Control. 1975. Shigella surveillance report no. 36, 1st and 2nd quarters. Center for Disease Control, Atlanta.

8. Cruickshank, R. 1960. Laboratory uses of antibiotics. Br. Med. Bull. 16:79-81.

9. Edwards, P. R., and W. H. Ewing. 1972. Identification of Enterobacteriaceae, 3rd ed. Burgess Publishing Co., Minneapolis.

10. Eichner, E. R., E. J. Gangarosa, and J. B. Goldsby. 1968. The current status of shigellosis in the United States. Am. J. Public Health 58:753-763.

11. Elek, S. D., J. R. Davies, and R. Miles. 1973. Resistotyping of Shigella sonnei. J. Med. Microbiol. 6:329 345.

12. Farmer, J. J., III. 1970. Mnemonic for reporting bacteriocin and bacteriophage types. Lancet ii:96.

13. Farmer, J. J., III. 1972. Epidemiological differentiation of Serratia marcescens: typing by bacteriocin production. Appl. Microbiol. 23:218-225.

14. Farrant, W. H., and A. J. H. Tomlinson. 1966. Some 
studies on the epidemiology of Sonne dysentery. Changes in colicin type and antibiotic resistance between 1956-1965. J. Hyg. 64:287-303.

15. Gangarosa, E. J., and H. L. DuPont. 1973. Bacillary dysentery, p. 203-204. In H. F. Conn and R. B. Conn., Jr., (ed.), Current diagnosis. W. B. Saunders Publishing Co., Philadelphia.

16. Gillies, R. R. 1964. Colicine production as an epidemiological marker of Shigella sonnei. J. Hyg. 62:1-9.

17. Gillies, R. R. 1965. Fermentation studies on Shigella sonnei. J. Pathol. Bacteriol. 90:345-348.

18. Gromkova, R., and A. Trifonova. 1967. Attempts at phage typing of Shigella sonnei. Zentralbl. Bakteriol. Parasitenkd. Infektionskr. 204:212-215.

19. Hammarstrom, E. 1949. Phage typing of Shigella sonnei. Acta Med. Scand. 133(Suppl. 223):1-132.

20. Laszlo, V. G., and L. Kerekes. 1969. Phage and colicin typing of Shigella sonnei. Acta. Microbiol. Acad. Sci. Hung. 16:309-317.

21. Ludford, C. G. 1953. Bacteriophage types of Shigella sonnei in Queensland, Austral. J. Exp. Biol. 31:545552.

22. Mayr-Harting, A. 1952. The phage typing of Shigella sonnei, and the limits of type stability. J. Gen. Microbiol. 7:382-396.
23. Morris, G. K., and J. G. Wells. 1974. Colicin typing of Shigella sonnei. Appl. Microbiol. 27:312-316.

24. Mulezyk, M., and S. Slopek. 1973. Use of a new phage preparation in prophylaxis and treatment of shigellosis. Acta. Microbiol. Acad. Sci. Hung. 21:115-119.

25. Parisi, J. T., J. C. Russel, and R. J. Merlo. 1969. Bacteriophage typing as an epidemiological tool for urinary Escherichia coli. Appl. Microbiol. 17:721-725.

26. Reller, L. B. 1971. Colicin typing as an epidemiologic tool in investigations of outbreaks of Shigella sonnei. Appl. Microbiol. 21:21-26.

27. Rishe, H. 1968. Phage typing of Shigella sonnei according to Hammarstrom's current experiences and completion of the method by temperature phages. Arch. Immuno. Ther. Exp. (Warsz) 16:392-401.

28. Slopek, S. I., Dublakowa, A. Kucharewiczkrubkowska, and T. Krzywy. 1973. Phage typing of Shigella sonnei. Arch. Immunol. Ther. Exp. (Warsz) 21(1):1-161.

29. Szturm-Rubinstein, S. 1968. Determination of biotype, phage type, and colicinogen character of Shigella son$n e i$, and its epidemiologic importance. Arch. Immunol. Ther. Exp. 16:421-428.

30. Zierdt, C. H., and P. J. Schmidt. 1964. Dissociation in Pseudomonas aeruginosa. J. Bacteriol. 87:1003-1010. 